\title{
REVIEW
}

Open Access

\section{The effects of inositol supplementation on lipid profiles among patients with metabolic diseases: a systematic review and meta-analysis of randomized controlled trials}

Reza Tabrizi ${ }^{1}$, Vahidreza Ostadmohammadi ${ }^{2}$, Kamran B. Lankarani ${ }^{3}$, Payam Peymani ${ }^{3}$, Maryam Akbari ${ }^{1}$, Fariba Kolahdooz ${ }^{4}$ and Zatollah Asemi ${ }^{2^{*}}$ (D)

\begin{abstract}
Background: Several studies have evaluated the effect of inositol supplementation on lipid profiles among population with metabolic diseases; however, the findings are controversial. This review of randomized controlled trials (RCTs) was performed to summarize the evidence of the effects of inositol supplementation on lipid profiles among population with metabolic diseases.

Methods: Relevant RCTs studies were searched in Cochrane Library, EMBASE, MEDLINE, and Web of Science until October 2017. Two researchers assessed study eligibility, extracted data, and evaluated risk of bias of included primary studies, independently. To check for the heterogeneity among included studies Q-test and $I_{2}$ statistics were used. Data were pooled by using the random-effect model and standardized mean difference (SMD) was considered as summary of the effect size.

Results: Overall, 14 RCTs were included into meta-analysis. Pooled results showed that inositol supplementation among patients with metabolic diseases significantly decreased triglycerides (SMD $-1.24 ; 95 \% \mathrm{Cl},-1.84,-0.64$; $P<0.001)$, total- $(S M D-1.09 ; 95 \% C l,-1.83,-0.55 ; P<0.001)$, and LDL-cholesterol levels (SMD $-1.31 ; 95 \% \mathrm{Cl}$, $-2.23,-0.39 ; P=0.005$ ). There was no effect of inositol supplementation on HDL-cholesterol levels (SMD 0.20; $95 \% \mathrm{Cl},-0.27,0.67 ; P=0.40)$.
\end{abstract}

Conclusions: Inositol supplementation may result in reduction in triglycerides, total- and LDL-cholesterol levels, but did not affect HDL-cholesterol levels among patients with metabolic diseases. Additional prospective studies regarding the effect of inositol supplementation on lipid profiles in patients with metabolic diseases are necessary.

Keywords: Inositol, Lipid profiles, Metabolic diseases, Meta-analysis

\footnotetext{
* Correspondence: asemi_r@yahoo.com

${ }^{2}$ Research Center for Biochemistry and Nutrition in Metabolic Diseases,

Kashan University of Medical Sciences, Kashan, Islamic Republic of Iran

Full list of author information is available at the end of the article
}

(c) The Author(s). 2018 Open Access This article is distributed under the terms of the Creative Commons Attribution 4.0 International License (http://creativecommons.org/licenses/by/4.0/), which permits unrestricted use, distribution, and reproduction in any medium, provided you give appropriate credit to the original author(s) and the source, provide a link to the Creative Commons license, and indicate if changes were made. The Creative Commons Public Domain Dedication waiver (http://creativecommons.org/publicdomain/zero/1.0/) applies to the data made available in this article, unless otherwise stated. 


\section{Background}

There are numerous primary and secondary causes of hypertriglyceridemia and hypercholesterolemia, such as genetics, lifestyle and diet, especially obesity and physical inactivity, diseases, including metabolic syndrome (MetS), hyperinsuliemia, diabetes mellitus, and renal disease $[1,2]$. The incidence of elevated triglycerides levels varies by age, and is consistently higher in men than women [3]. Previous studies have demonstrated that hypertriglyceridemia is often correlated with insulin resistance, and chronic disease, including type 2 diabetes mellitus (T2DM) and chronic kidney disease [3, 4]. In addition, increased levels of totaland LDL-cholesterol are associated with an increased risk of atherosclerotic cardiovascular diseases (CVD) [5].

Various approaches are suggested to control blood glucose and lipid profiles, including lifestyle modification and pharmacological therapy $[6,7]$. One such emerging potential intervention is inositols supplementation (e.g. myo-inositol (MI) and di-chiro inositol (DCI)) which showed insulin-mimetic properties efficient in lowering post-prandial blood glucose [8]. $M I$ is the primary biologically active form of inositol which has a six-carbon sugar alcohol and is one of nine biologically significant isomers of hexahydroxycyclohexane [9]. DCI is also active and recognized as an important messenger in insulin signal transduction [9]. Inositols are present in many foods, especially fresh fruits and vegetables, beans, grains, and, nuts. Inositols have been mainly used in treating several pathologies including polycystic ovary syndrome (PCOS) [10], MetS [11], and gestational diabetes (GDM) [12]. The favorable effects of a dietary supplement of inositols have been studied in the last years $[13,14]$. In a meta-analysis study conducted by Pundir et al. [15], inositols supplementation could improve menstrual cycles, ovulation and metabolic changes in patients with PCOS. Moreover, Giordano et al. [11] demonstrated that MI supplementation significantly improved systolic and diastolic blood pressure, insulin resistance, cholesterol, and triglycerides levels in postmenopausal women with MetS. In lean subjects with PCOS, DCI supplementation decreased circulating levels of insulin, serum androgens, and improved some of the metabolic abnormalities such as increased blood pressure and hypertriglyceridemia [16].

Many randomized controlled trials (RCTs) have been conducted to determine whether inositol supplementation has a causal effect on lipid profiles among population with metabolic diseases. We aimed to systematically review the present evidence on the effect of inositol supplementation on lipid profiles in RCTs and to summarize the available findings in a meta-analysis, if possible.

\section{Methods}

\section{Search strategy}

Relevant studies were systematically searched from online databases PubMed, EMBASE, Web of Science, and
Cochrane Library databases, until October 2017 by using the following $\mathrm{MeSH}$ and text words keywords: patients ["metabolic disease" OR "Mets" OR "diabetes" OR “T2DM" OR “GDM" OR "PCOS”], intervention ("MI” OR "inositol" OR "DCI" OR "DCI" AND "supplementation" OR "administration" OR "taking" OR "intake"), and outcomes ["triglycerides (TG)" OR "total-cholesterol" OR "low-density lipoprotein cholesterol (LDL-cholesterol)" OR "high-density lipoprotein cholesterol (HDL-cholesterol)"]. International Standard Randomized Controlled Trial Number Register and Meta-register for RCTs were searched for finding ongoing and archived RCTs. The search study was conducted by two independent researchers. References cited in the selected studies were manually searched for additional relevant articles. Our search was restricted to studies published in English.

\section{Selection criteria}

The eligibility criteria were: human RCTs, patients with metabolic diseases, the administration of inositol supplements, studies that were compared the inositol group with control or placebo group, and studies that have reported mean changes of lipid profiles including triglycerides, total-, LDL-, and HDL-cholesterol along with standard deviation for the intervention and control groups. Studies that did not report mean changes of lipid profiles, along with standard deviation (SD) for the intervention and control groups, the abstracts of seminars without full text, case reports, and studies that did not obtain the minimum required score of quality assessment process were excluded.

\section{Quality assessment}

Two authors have performed data extraction (VO and MA) and quality assessment (RT and MA), independently when there was disagreement between them were resolved by a third author (ZA). We used the Cochrane Collaboration risk of bias tool to assess the quality of the included RCTs based on information on the following domains: randomization generation, allocation concealment, blinding, analyses with intention to treat, withdrawals and drop-outs data, selective reporting, other sources of bias.

\section{Statistical methods}

RevMan software (Cochrane Review Manager, version 5.2) and STATA version 12.0 (Stata Corp., College Station, TX) were used for data analyses. Heterogeneity was evaluated through the Cochran $(\mathrm{Q})$ and I-squared tests $\left(\mathrm{I}_{2}\right)$. Given the existing heterogeneity between studies, when $\mathrm{I}_{2}$ exceeds $50 \%$ or $P<0.05$, the random-effect model was used; otherwise, the fixed-effect model was applied. Inverse variance method and Cohen statistics were used for estimation of standardized mean difference (SMD) and 95\% CI for verifying the outcomes behavior of each study group (intervention/control). Sensitivity analyses also undertook 
in the trials one by one to evaluate the reliability of the pooled mean difference. In addition, the Cochrane Collaboration Risk of Bias tool was used to assess the methodological quality of the RCTs. Potential publication bias was assessed through visual inspection of funnel plots and quantitatively assessed using Egger's tests.

\section{Results}

\section{Characteristics of included studies}

From 956 potential citations, 14 articles were included in our meta-analysis. The flow chart of step by step details for study identification and selection is illustrated in Fig. 1. Eight studies were used double-blind design [16-23], four were randomized placebo-controlled trial design [11, 24-26], and two were randomized controlled trial design [27, 28]. Seven trials evaluated the effects of inositol on lipid profiles among patients with PCOS $[16,19,20,22,23,27,28]$ and others were evaluated the effects of inositol on other metabolic diseases [11, 17, 18, 21, 24-26]. Twelve studies have reported the effects of inositol on triglycerides, 11 on total cholesterol, five on LDL-cholesterol, and ten on HDL-cholesterol levels.
These articles have been published from 1999 to 2017 . Eleven studies were conducted in Italy [11, 17-20, 22, 24-28], two in Venezuela [16, 23], and one in Republic of Korea [21]. The mean age of included participants was ranged between $22.79 \pm 4.13$ to $61.7 \pm 7.74$ yeras. The duration of intervention ranged between 6 weeks to 12 months. The dosage of inositol (including its derivatives such as MI and/or DCI) varied from $688 \mathrm{mg}$ to $4000 \mathrm{mg} /$ day. Table 1 shows characteristics of the included trials.

The quality assessment of the included studies, using the Cochrane Collaboration risk of bias tool is presented in Fig. 2.

Our meta-analysis findings showed that inositol supplementation among patients with metabolic diseases significantly decreased triglycerides (SMD - 1.24; 95\% CI $-1.84,-0.64 ; P<0.001$ ), total- (SMD $-1.09 ; 95 \% \mathrm{CI}$, $-1.83,-0.55 ; \quad P<0.001$ ), and LDL-cholesterol levels (SMD - 1.31; 95\% CI, $-2.23,-0.39 ; P=0.005$ ) (Table 2 and Fig. 3). Inositol supplementation did not affect the HDL-cholesterol levels (SMD 0.20; 95\% CI, - 0.27, 0.67; $P=0.40)$.

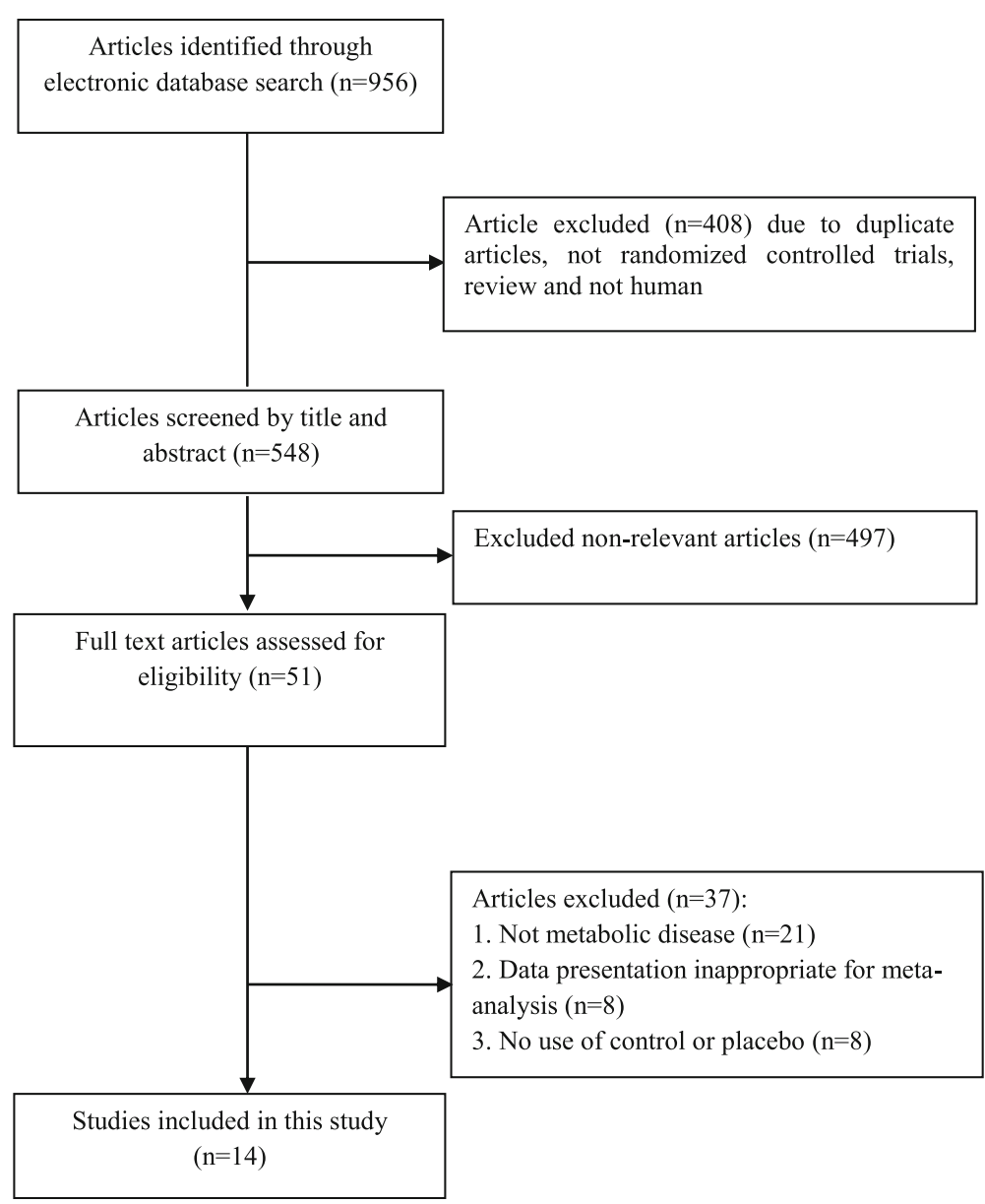

Fig. 1 Literature search and review flowchart for selection of studies 


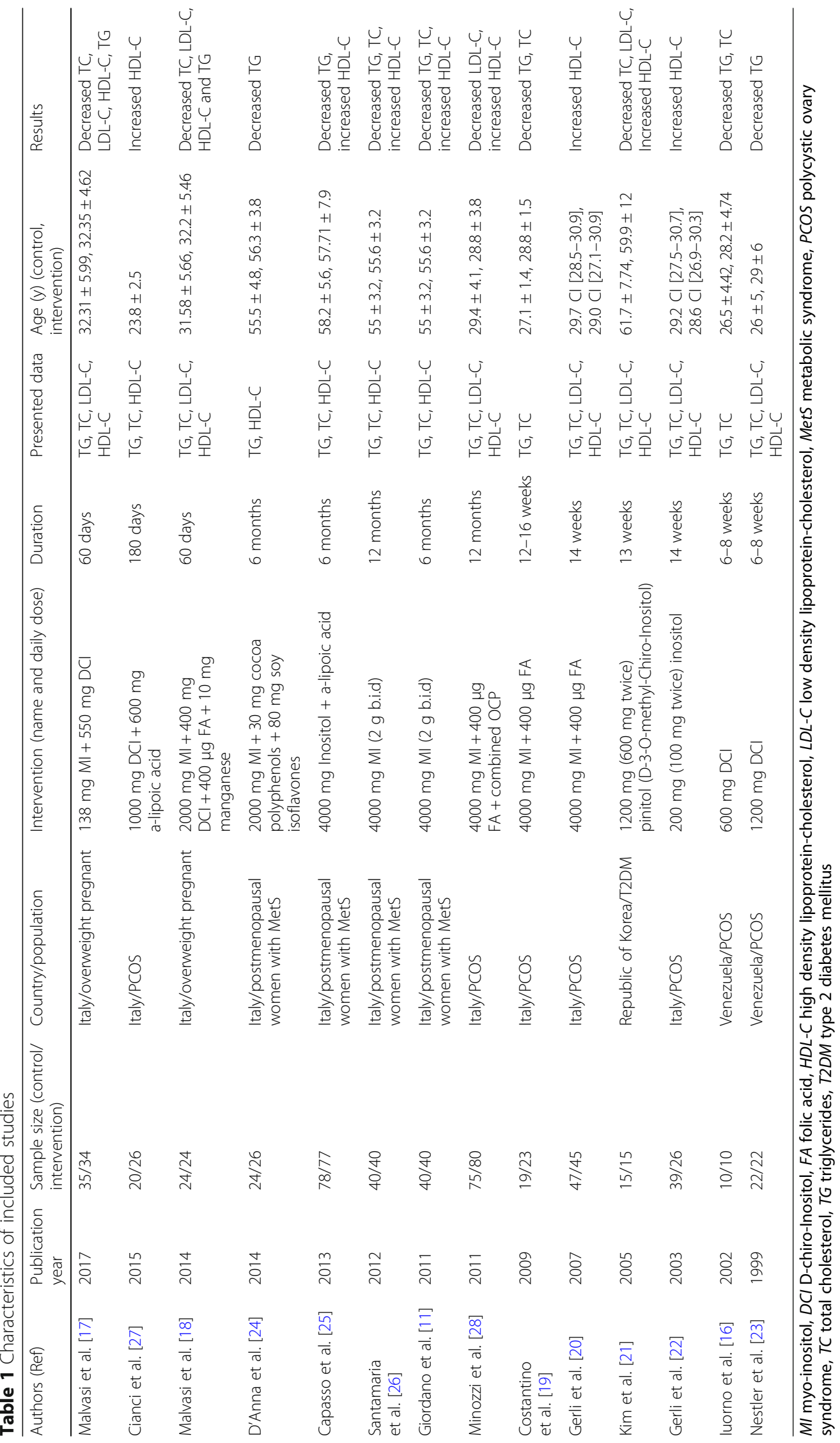




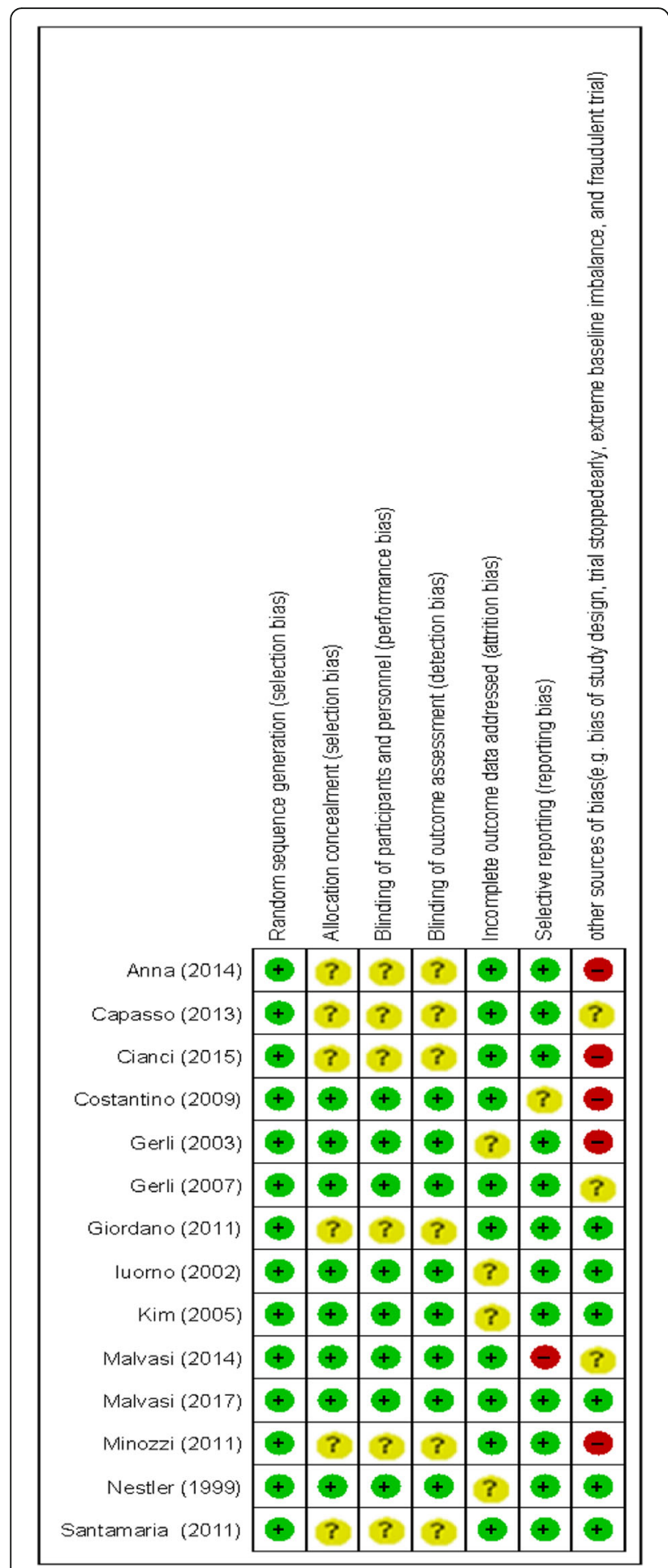

Fig. 2 The methodological quality of included studies (risk of bias)

Because of the heterogeneity between included studies, we performed multiple subgroup analyses by suspected variables including type of disease, dosage of inositol, and duration of the study. The results demonstrated that the heterogeneity decreased in a number of subgroups, particularly in type of disease and the duration of study for triglycerides and HDL-cholesterol (Table 3).

\section{Effects of inositol supplementation on triglycerides levels} In stratified analyses by inositol, the non-PCOS category had the strongest effect on reducing triglycerides levels (SMD: - 1.58; 95\%CI: - 2.32, - 0.85; $\mathrm{I}^{2}: 92.1 \%$ ) compared to the studies with PCOS patients (Table 3). In addition, in stratified analyses by the dosage of inositol, the $<2000 \mathrm{mg} /$ day category had the strongest effect on reducing triglycerides levels (SMD: $-1.69 ; 95 \% \mathrm{CI}$ : 2.94 , $-0.34 ; \mathrm{I}^{2}: 93.4 \%$ ) compared to the $\geq 2000 \mathrm{mg} /$ day category. In stratified analyses by the duration of study, the $<14$ weeks category had the strongest effect on reducing triglycerides levels (SMD: $-0.99 ; 95 \% \mathrm{CI}$ : $-1.67,-0.32$; $\left.\mathrm{I}^{2}: 93.1 \%\right)$ compared to the $\geq 14$ weeks category. In stratified analyses by the type of interventions, the MI category (SMD: -1.15 ; 95\% CI, $-1.91,-0.39 ; \mathrm{I}^{2}: 94.0 \%$ ) and MI plus DCI category (SMD - 3.37; 95\% CI, - 6.00, - 0.75; $\left.\mathrm{I}^{2}: 94.2 \%\right)$ had the strongest effect on reducing triglycerides levels compared with the DCI category.

\section{Effects of inositol supplementation on total cholesterol levels} In stratified analyses by inositol, the non-PCOS category had the strongest effect on decreasing total cholesterol concentrations (SMD: - 1.49; 95\%CI: - 2.51, - 0.46; $\left.\mathrm{I}^{2}: 95.5 \%\right)$ compared to the PCOS category (Table 3). In addition, in stratified analyses by the dosage of inositol, the $<2000 \mathrm{mg} /$ day category had the strongest effect on decreasing total cholesterol concentrations (SMD: -1.51 ; 95\% CI: $\left.-2.38,-0.63 ; \mathrm{I}^{2}: 95.2 \%\right)$ compared to the $\geq 2000 \mathrm{mg} /$ day category. In stratified analyses by the duration of study, the $\geq 14$ weeks category had the strongest effect on decreasing total cholesterol concentrations (SMD: - 1.77; 95\% CI: $-3.31,-0.22$; $\left.\mathrm{I}^{2}: 95.0 \%\right)$ compared to the $<14$ weeks category. In stratified analyses by type of intervention, the MI category (SMD: -0.91 ; 95\% CI, -1.59 , $\left.-0.24 ; \mathrm{I}^{2}: 91.9 \%\right)$ and MI plus DCI category (SMD: - 3.76; $95 \% \mathrm{CI},-5.68,-1.85 ; \mathrm{I}^{2}: 88.2 \%$ ) had the strongest effect on reducing total cholesterol concentrations compared with the DCI category.

\section{Effects of inositol supplementation on LDL-cholesterol levels}

In stratified analyses by the dosage of inositol, the $<2000 \mathrm{mg} /$ day category had the strongest effect on decreasing LDL-cholesterol levels (SMD: -2.0 ; 95\% CI: $\left.-3.98,-0.03 ; \mathrm{I}^{2}: 94.8 \%\right)$ compared to the $\geq 2000 \mathrm{mg} /$ day category (Table 3 ). In stratified analyses by the duration of study, the $<14$ weeks category had the strongest effect on decreasing LDL-cholesterol levels (SMD: 1.03; 95\%CI: $-1.37,-0.70)$ compared to the $\geq 14$ weeks category. LDL-cholesterol levels did not influence by type 
Table 2 Estimation of the standardized difference means of related indictors with Cl 95\% between the intervention and placebo groups

\begin{tabular}{|c|c|c|c|c|c|c|c|}
\hline \multirow[t]{2}{*}{ Variables } & & \multirow{2}{*}{$\begin{array}{l}\text { Number } \\
\text { of study }\end{array}$} & \multirow{2}{*}{$\begin{array}{l}\text { Standardized } \\
\text { mean difference }\end{array}$} & \multirow[t]{2}{*}{$\mathrm{Cl} 95 \%$} & \multicolumn{3}{|l|}{ Heterogeneity } \\
\hline & & & & & I-squared (\%) & Q & $P$-value \\
\hline \multirow[t]{3}{*}{ Triglycerides } & Intervention group (after vs. before) & 12 & -1.84 & $-2.62,-1.06$ & 95.6 & 248.31 & $<0.001$ \\
\hline & Placebo group (after vs. before) & 12 & -0.17 & $-0.39,0.05$ & 53.9 & 23.84 & 0.01 \\
\hline & Intervention group vs. placebo group & 12 & -1.24 & $-1.84,-0.64$ & 93.2 & 161.55 & $<0.001$ \\
\hline \multirow[t]{3}{*}{ Total cholesterol } & Intervention group (after vs. before) & 11 & -1.40 & $-2.11,-0.69$ & 94.7 & 189.67 & $<0.001$ \\
\hline & Placebo group (after vs. before) & 11 & 0.22 & $-0.17,0.61$ & 84.7 & 65.30 & $<0.001$ \\
\hline & Intervention group vs. placebo group & 11 & -1.19 & $-1.83,-0.55$ & 93.6 & 156.53 & $<0.001$ \\
\hline \multirow[t]{3}{*}{ LDL-cholesterol } & Intervention group (after vs. before) & 5 & -1.28 & $-2.37,-0.18$ & 94.4 & 71.88 & $<0.001$ \\
\hline & Placebo group (after vs. before) & 5 & 0.23 & $0.02,0.44$ & 0.00 & 3.13 & 0.53 \\
\hline & Intervention group vs. placebo group & 5 & -1.31 & $-2.23,-0.39$ & 92.2 & 51.00 & $<0.001$ \\
\hline \multirow[t]{3}{*}{ HDL-cholesterol } & Intervention group (after vs. before) & 10 & 0.37 & $-0.13,0.87$ & 90.7 & 96.93 & $<0.001$ \\
\hline & Placebo group (after vs. before) & 10 & -0.02 & $-0.20,0.15$ & 27.2 & 12.37 & 0.19 \\
\hline & Intervention group vs. placebo group & 10 & 0.20 & $-0.27,0.67$ & 89.4 & 84.52 & $<0.001$ \\
\hline
\end{tabular}

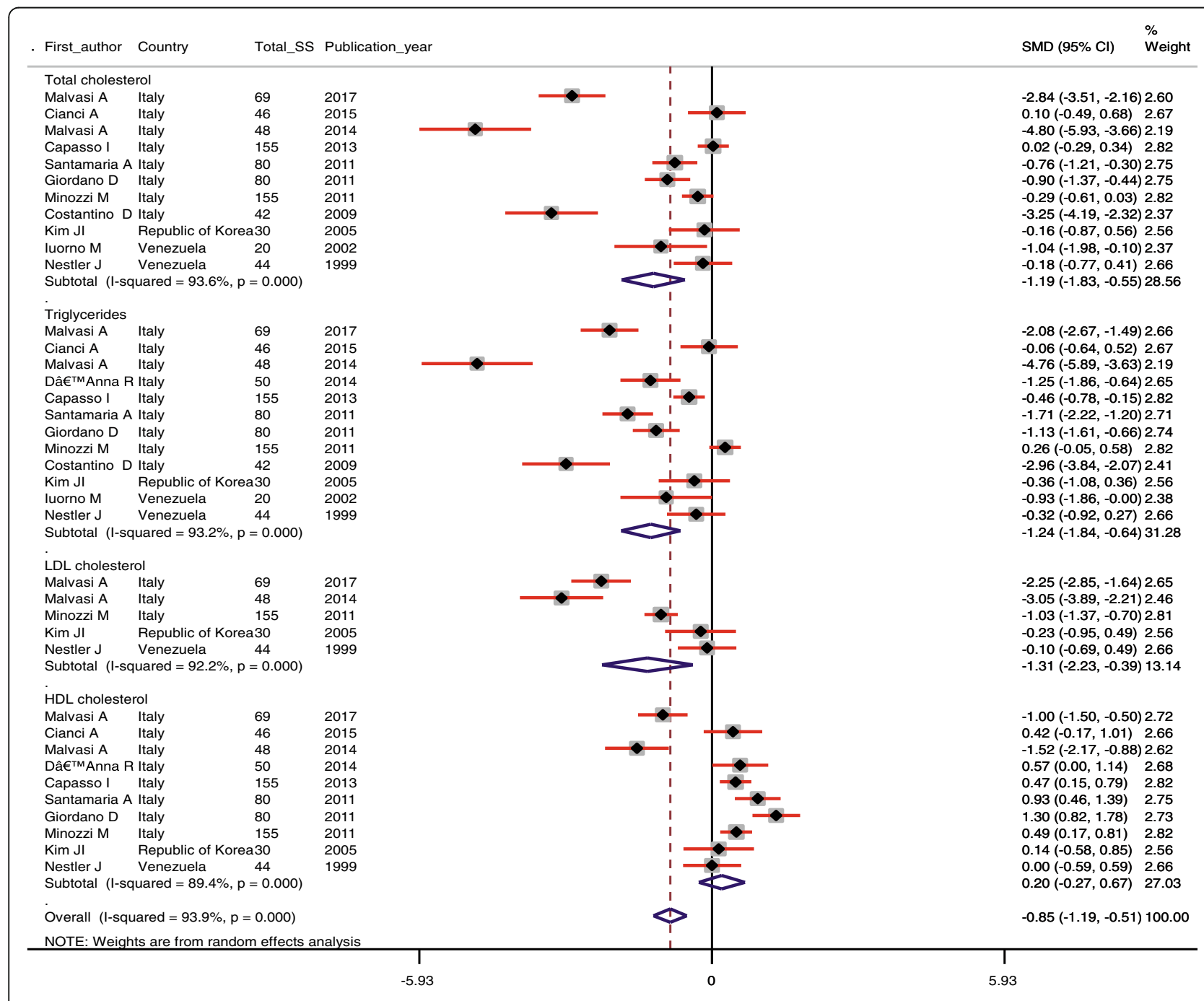

Fig. 3 Meta-analysis lipid profiles standardized mean differences estimates for lipid profiles in inositol and placebo groups $(\mathrm{Cl}=95 \%)$ 
Table 3 The association between inositol intake and lipid profiles based on subgroup analysis

\begin{tabular}{|c|c|c|c|c|c|c|c|}
\hline Variables & & Number of SMD included & Subgroups & $\begin{array}{l}\text { Pooled OR } \\
\text { (random effect) }\end{array}$ & $95 \% \mathrm{Cl}$ & $I^{2}(\%)$ & Overall $I^{2}(\%)$ \\
\hline \multirow[t]{9}{*}{ Triglycerides } & \multirow[t]{2}{*}{ Type of disease } & 5 & PCOS & -0.74 & $-1.66,0.18$ & 91.7 & \multirow[t]{9}{*}{93.2} \\
\hline & & 7 & Non-PCOS & -1.58 & $-2.32,-0.85$ & 92.1 & \\
\hline & \multirow[t]{2}{*}{ Dosage of inositol (mg/day) } & 6 & $\geq 2000$ & -0.83 & $-1.49,-0.18$ & 83.4 & \\
\hline & & 6 & $<2000$ & -1.69 & $-2.69,-0.68$ & 96.2 & \\
\hline & \multirow[t]{2}{*}{ Duration of study (week) } & 5 & $\geq 14$ & -1.64 & $-2.94,-0.34$ & 93.4 & \\
\hline & & 7 & $<14$ & -0.99 & $-1.67,-0.32$ & 93.1 & \\
\hline & \multirow[t]{3}{*}{ Type of intervention } & 4 & $\mathrm{DCl}$ & -0.32 & $-0.66,0.01$ & 0.0 & \\
\hline & & 6 & Ml & -1.15 & $-1.91,-0.39$ & 94.0 & \\
\hline & & 2 & $\mathrm{Ml}+\mathrm{DCl}$ & -3.37 & $-6.00,-0.75$ & 94.2 & \\
\hline \multirow[t]{9}{*}{ Total cholesterol } & \multirow[t]{2}{*}{ Type of disease } & 5 & PCOS & -0.86 & $-1.72,-0.02$ & 90.3 & \multirow[t]{9}{*}{93.6} \\
\hline & & 6 & Non-PCOS & -1.49 & $-2.51,-0.46$ & 95.5 & \\
\hline & \multirow[t]{2}{*}{ Dosage of inositol (mg/day) } & 5 & $\geq 2000$ & -0.82 & $-1.91,0.28$ & 92.2 & \\
\hline & & 6 & $<2000$ & -1.51 & $-2.38,-0.63$ & 95.2 & \\
\hline & \multirow[t]{2}{*}{ Duration of study (week) } & 5 & $\geq 14$ & -1.77 & $-3.31,-0.22$ & 95.0 & \\
\hline & & 6 & $<14$ & -0.74 & $-1.33,-0.15$ & 90.5 & \\
\hline & \multirow[t]{3}{*}{ Type of intervention } & 4 & $\mathrm{DCl}$ & -0.22 & $-0.62,0.18$ & 26.2 & \\
\hline & & 5 & Ml & -0.91 & $-1.59,-0.24$ & 91.9 & \\
\hline & & 2 & $\mathrm{Ml}+\mathrm{DCl}$ & -3.76 & $-5.68,-1.85$ & 88.2 & \\
\hline \multirow[t]{9}{*}{ LDL-cholesterol } & \multirow[t]{2}{*}{ Type of disease } & 3 & PCOS & -0.60 & $-1.51,0.31$ & 86.1 & \multirow[t]{9}{*}{92.2} \\
\hline & & 2 & Non-PCOS & -1.84 & $-3.41,0.26$ & 93.1 & \\
\hline & \multirow[t]{2}{*}{ Dosage of inositol (mg/day) } & 3 & $\geq 2000$ & -0.86 & $-2.27,0.54$ & 93.2 & \\
\hline & & 2 & $<2000$ & -2.00 & $-3.98,-0.03$ & 94.8 & \\
\hline & \multirow[t]{2}{*}{ Duration of study (week) } & 4 & $\geq 14$ & -1.39 & $-2.78,-0.01$ & 94.0 & \\
\hline & & 1 & $<14$ & -1.03 & $-1.37,-0.70$ & 0.0 & \\
\hline & \multirow[t]{3}{*}{ Type of intervention } & 2 & $\mathrm{DCl}$ & -0.15 & $-0.61,0.30$ & 0.0 & \\
\hline & & 1 & $\mathrm{Ml}$ & -1.03 & $-1.37,-0.70$ & - & \\
\hline & & 2 & $\mathrm{Ml}+\mathrm{DCl}$ & -2.59 & $-3.39,-1.81$ & 56.7 & \\
\hline \multirow[t]{9}{*}{ HDL-cholesterol } & \multirow[t]{2}{*}{ Type of disease } & 3 & PCOS & 0.38 & $0.12,0.64$ & 2.4 & \multirow[t]{9}{*}{89.4} \\
\hline & & 7 & Non-PCOS & 0.14 & $-0.56,0.84$ & 92.7 & \\
\hline & \multirow[t]{2}{*}{ Dosage of inositol (mg/day) } & 5 & $\geq 2000$ & 0.01 & $-0.59,0.62$ & 81.1 & \\
\hline & & 5 & $<2000$ & 0.37 & $-0.31,1.04$ & 92.2 & \\
\hline & \multirow[t]{2}{*}{ Duration of study (week) } & 4 & $\geq 14$ & -0.61 & $-1.35,0.14$ & 83.5 & \\
\hline & & 6 & $<14$ & 0.68 & $0.42,0.95$ & 55.1 & \\
\hline & \multirow[t]{3}{*}{ Type of intervention } & 3 & $\mathrm{DCl}$ & 0.19 & $-0.17,0.55$ & 0.0 & \\
\hline & & 5 & $\mathrm{Ml}$ & 0.72 & $0.42,1.02$ & 62.0 & \\
\hline & & 2 & $\mathrm{Ml}+\mathrm{DCl}$ & -1.22 & $-1.73,-0.71$ & 36.2 & \\
\hline
\end{tabular}

MI myo-inositol, DCI D-chiro-Inositol, $P C O S$ polycystic ovary syndrome

of diseases after inositol intake. In stratified analyses by type of intervention, the MI category (SMD: - 1.03; $95 \% \mathrm{CI},-1.37,-0.70$ ) and MI plus DCI category (SMD: $-2.59 ; 95 \% \mathrm{CI},-3.39,-1.81 ; \mathrm{I}^{2}: 56.7 \%$ ) had the strongest effect on decreasing LDL-cholesterol levels compared with the DCI category.

\section{Effects of inositol supplementation on HDL-cholesterol levels}

In stratified analyses by inositol, the PCOS category had the strongest effect on increasing HDL-cholesterol levels (SMD: 0.38; 95\%CI: 0.12, 2.4; $\mathrm{I}^{2}: 2.4 \%$ ) compared to the non-PCOS category (Table 3 ). In stratified analyses by 
the duration of study, the $<14$ weeks category had the strongest effect on increasing HDL-cholesterol levels (SMD: 0.68; 95\%CI: 0.42, 0.95; $\mathrm{I}^{2}: 55.1 \%$ ) compared to the $\geq 14$ weeks category. HDL-cholesterol levels did not influence by dosage used after inositol intake. In stratified analyses by the type of intervention, the MI category had the strongest effect on increasing HDL-cholesterol levels (SMD: 0.72; 95\% CI, 0.42, 1.02; I2:55.1\%; I²:62.0\%) compared with the DCI category. While, MI plus DCI category significantly decreased HDL-cholesterol (SMD: - 1.22; 95\% CI, $\left.-1.73,-0.71 ; \mathrm{I}^{2}: 36.2 \%\right)$.

\section{Sensitivity analysis and publication bias}

Sensitivity analysis did not show any significant change regarding the effect of inositol on triglycerides, total-, LDL- and HDL-cholesterol after excluding each trial from meta-analysis one by one (Fig. 4).

There was no evidence of publication bias for meta-analyses assessing the effects of inositol on LDL$(\mathrm{B}=-2.63, P=0.65)$, and HDL-cholesterol $(\mathrm{B}=-3.90$, $P=0.30$ ) with Egger's regression test.

There was evidence of publication bias on triglycerides $(\mathrm{B}=-6.99, P=0.01)$ and total cholesterol $(\mathrm{B}=-6.87, P=$ 0.01 ), therefore we used non-parametric method (Duval and Tweedie) to estimate the results of censored studies. The meta-analysis based on these studies showed that summary effect size on total cholesterol was not significant between before (SMD - 1.19; 95\% CI, - 1.83, - 0.55) included censored studies into meta-analysis and after (SMD - 1.33; 95\% CI, - 2.00, - 0.66). In addition, summary effect size SMD of triglycerides increased form before (SMD - 1.24; 95\% CI, - 1.84, - 0.64) to after (SMD - 1.54; $95 \% \mathrm{CI},-2.30,-0.79)$ included censored studies into meta-analysis.

\section{Discussion}

To our knowledge, this is the first meta-analysis of RCTs that evaluated the effect of inositol supplementation on lipid profiles among populations with metabolic diseases. We found that inositol supplementation may result in an improvement in triglycerides, total- and LDL-cholesterol levels, but did not affect HDL-cholesterol levels among populations with metabolic diseases.

Therapeutic lifestyle changes aimed at pursuing an acceptable control of risk factors of metabolic disturbances, including dyslipidemia and hyperglycemia, are limited by poor adherence and persistence $[29,30]$. A general consensus already exists on the first line approach in peoples with metabolic diseases which includes the lifestyle modifications, including diet, physical exercise and regular sleep pattern. However, we believe that implementation of behavioral changes cannot be easily reached by every patient and/or in all situation, resulting poor compliance. Since insulin resistance is the major driver of MetS, the use of insulin sensitizer is therefore well established, in order to decrease comorbidities that characterize MetS [31]. Some studies have demonstrated the beneficial effects of inositol supplementation on lipid profiles in patients with metabolic status; however, findings are controversial. For example, Kim et al. [21] demonstrated that inositol supplementation for 13 weeks to patients with T2DM significantly decreased total-, LDL-, LDL/HDL-cholesterol ratio, and significantly increased HDL-cholesterol, but did not affect triglycerides levels. In addition, inositol supplementation at a dosage of $1200 \mathrm{mg} /$ day for 6 to 8 weeks among obese women with PCOS improved the action of insulin, ovulatory function, androgen levels, blood pressures, and triglycerides levels [23]. A significant reduction in triglycerides $(-43.2 \%)$ and a significant increase in HDL-cholesterol levels (48.6\%) were also evidenced following the supplementation with inositol for 6 months in postmenopausal women with MetS, but did not affect other lipid profiles [25]. In a meta-analysis study by Pundir et al. [15], inositols significantly improved menstrual cycles, ovulation and metabolic changes in PCOS. Irrespective of the speculative assumptions on the possible beneficial effects of triglycerides and HDL-cholesterol increase, there is substantial agreement that high triglycerides, total- and LDL-cholesterol, and low HDL-cholesterol concentrations have a detrimental influence on CVD prognosis [32, 33]. In addition, previous studies have reported that nutraceuticals play a peculiar role in ameliorating human dyslipidaemia [34, 35], which in turn effectively able to reduce the burden of the atherosclerosis process and the progress of CVD [36]. Nutraceuticals may improve lipid profiles through the upregulation of hepatic LDL receptors, decrease in the intestinal absorption of cholesterol [37], blocking carbohydrate digestion and glucose absorption in the gut, decreasing glucose release from liver, and activating insulin receptors, and glucose uptake in insulin-sensitive tissues [38].

In this meta-analysis study, inositol supplementation had benefit on HDL-cholesterol levels in patients with PCOS; however, it should no effect on HDL-cholesterol levels in non-PCOS patients. Duration of study in the included trials was varied from 6 weeks to 12 months; in our subgroup analysis, duration of study $<14$ weeks was compared with $\geq 14$ weeks of inositol supplementation and showed a significantly beneficial effect on increasing circulating HDL-cholesterol levels with a longer duration of supplementation.

It has been suggested that the binding of insulin to specific receptors stimulates transport of inositol phosphoglycan intracellularly and explains its role as a mediator in the insulin signaling cascade [39]. Furthermore, decreasing insulin resistance after the intake of inositol may be due to an improvement in peripheral insulin sensitivity [40]. Decreasing insulin resistance may improve lipid 


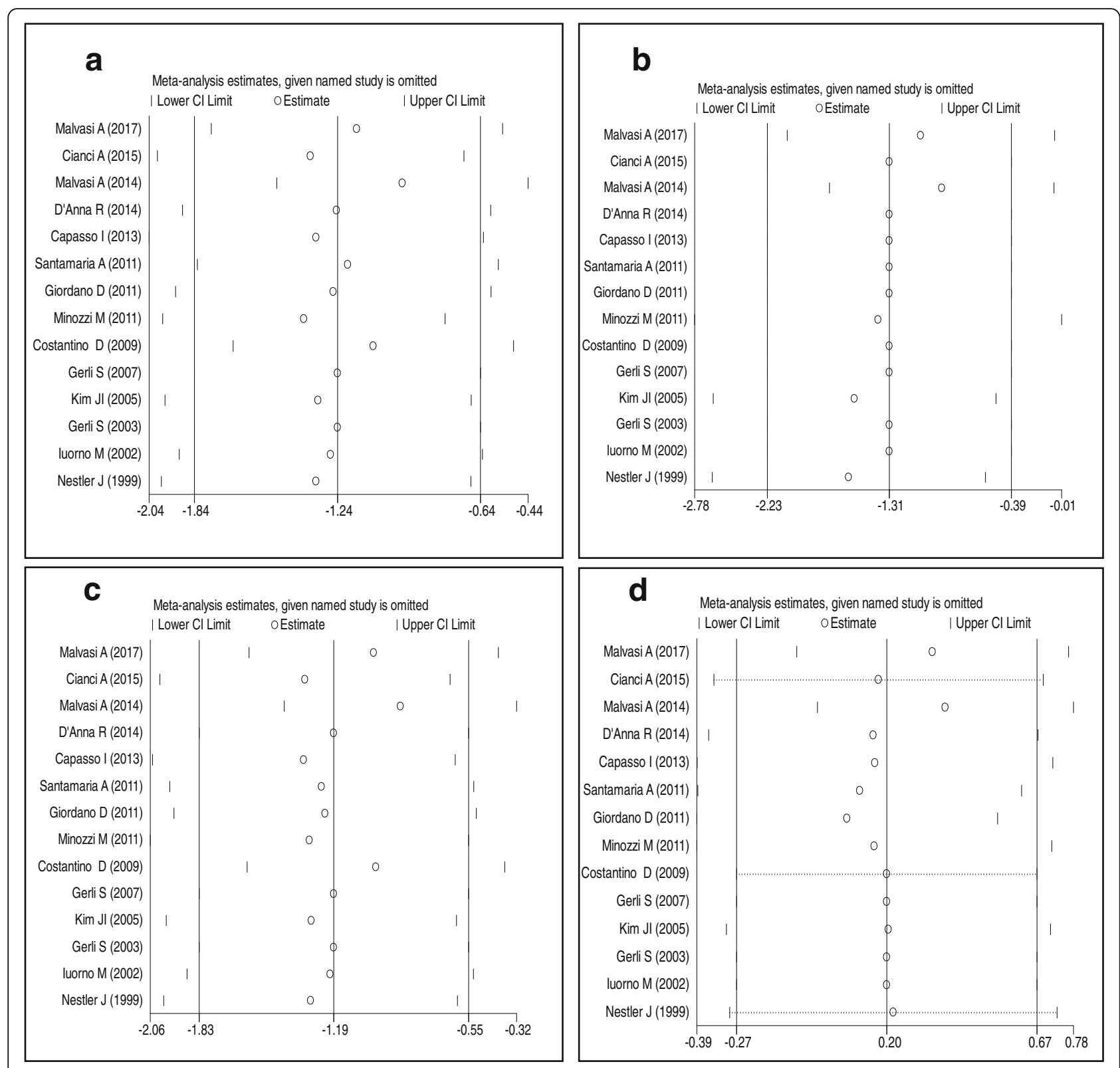

Fig. 4 Sensitivity analysis inositol on lipid profiles; (a) triglycerides, (b) total cholesterol, (c) LDL-cholesterol, (d) and HDL-cholesterol for assess the effects of every study on pooled standardized mean differences estimates

profiles. In addition, inositol intake may improve lipid metabolism through lowering visceral fat weight, hepatic lipid accumulation and insulin secretion as well as by increasing adiponectin concentrations [41]. Adipocytokine concentrations are associated with insulin sensitivity and resistance [42]. Adiponectin is the most important factor for increasing insulin sensitivity, while factors including leptin, resistin and C-reactive protein are known to be correlated with the increase of insulin resistance [43]. In a study, MI supplementation (4 g/day) for 8 weeks among patients with gestational diabetes significantly increased adiponectin levels [13]. In another study, co-supplementation with MI, soy isoflavones and cocoa polyphenols for 6 months among postmenopausal women with MetS significantly resistin levels [24]. Furthermore, a significant weight loss and leptin reduction following the administration of MI [20] my result in an improvement in the lipid profiles.

The current study had a few limitations. Various doses and different types of inositol were administered for intervention in the included studies. We were unable to assess the dose response association between supplementation and lipid profiles. There was high heterogeneity among included studies in our meta-analysis; however, 
heterogeneity decreased after sub-group analysis based on type of intervention. Our results should be interpreting with more caution.

\section{Conclusions}

Inositol supplementation may result in reduction in triglycerides, total- and LDL-cholesterol levels, but did not affect HDL-cholesterol levels among patients with metabolic diseases. Additional prospective studies regarding the effect of inositol supplementation on lipid profiles in patients with metabolic diseases are necessary.

\section{Abbreviations}

DCl: D-chiro-Inositol; FA: Folic acid; HDL-C: High density lipoprotein-cholesterol; LDL-C: Low density lipoprotein-cholesterol; MetS: Metabolic syndrome; MI: Myo-inositol; PCOS: Polycystic ovary syndrome; T2DM: Type 2 diabetes mellitus; TC: Total cholesterol; TG: Triglycerides

\section{Acknowledgements}

The present study was supported by a grant from the Vice-chancellor for Research, SUMS, Shiraz, and Iran.

\section{Funding}

The present study was founded by a grant from the Vice Chancellor for Research, Shiraz University of Medical Sciences, in Iran.

\section{Availability of data and materials}

The primary data for this study is available from the authors on direct request.

\section{Authors' contributions}

ZA contributed in conception, design, statistical analysis and drafting of the manuscript. RT, VO, KL, PP, MA and FK contributed in data collection and manuscript drafting. All authors approved the final version for submission. ZA supervised the study.

\section{Ethics approval and consent to participate}

This study was considered exempt by the SUMS Institutional Review Board.

\section{Competing interests}

The authors declare that they have no competing interests.

\section{Publisher's Note}

Springer Nature remains neutral with regard to jurisdictional claims in published maps and institutional affiliations.

\footnotetext{
Author details

${ }^{1}$ Health Policy Research Center, Institute of Health, Student Research Committee, Shiraz University of Medical Sciences, Shiraz, Iran. ${ }^{2}$ Research Center for Biochemistry and Nutrition in Metabolic Diseases, Kashan University of Medical Sciences, Kashan, Islamic Republic of Iran. ${ }^{3}$ Health Policy Research Center, Shiraz University of Medical Sciences, Shiraz, Iran. ${ }^{4}$ Indigenous and Global Health Research, Department of Medicine, University of Alberta, Edmonton, Canada.
}

Received: 3 April 2018 Accepted: 15 May 2018

Published online: 24 May 2018

\section{References}

1. Kushner PA, Cobble ME. Hypertriglyceridemia: the importance of identifying patients at risk. Postgrad Med. 2016;128(8):848-58.

2. Berglund L, Brunzell JD, Goldberg AC, Goldberg IJ, Sacks F, Murad MH, Stalenhoef AF. Evaluation and treatment of hypertriglyceridemia: an Endocrine Society clinical practice guideline. J Clin Endocrinol Metab. 2012; 97(9):2969-89.

3. Carroll M, Kit B, Lacher D. Trends in elevated triglyceride in adults: United States, 2001-2012. NCHS Data Brief. 2015;198:198.
4. Jacobson TA, Maki KC, Orringer CE, Jones PH, Kris-Etherton P, Sikand G, La Forge R, Daniels SR, Wilson DP, Morris PB, Wild RA, Grundy SM, Daviglus M, Ferdinand KC, Vijayaraghavan K, Deedwania PC, Aberg JA, Liao KP, McKenney JM, Ross JL, Braun LT, Ito MK, Bays HE, Brown WV, Underberg JA, NLA Expert Panel. National Lipid Association Recommendations for patientcentered Management of Dyslipidemia: part 2. J Clin Lipidol. 2015;966 Suppl):S1-122.e1.

5. Fulcher J, O'Connell R, Voysey M, Emberson J, Blackwell L, Mihaylova B, Simes J, Collins R, Kirby A, Colhoun H, Braunwald E, La Rosa J, Pedersen TR, Tonkin A, Davis B, Sleight P, Franzosi MG, Baigent C, Keech A. Efficacy and safety of LDL-lowering therapy among men and women: meta-analysis of individual data from 174,000 participants in 27 randomised trials. Lancet. 2015;385(9976):1397-405.

6. Lombardo F, Lunghi R, Pallotti F, Palumbo A, Senofonte G, Cefaloni AC, Gandini L, Lenzi A. Effects of a dietary supplement on cholesterol in subjects with moderate hypercholesterolemia. Clin Ter. 2013;164(3):e147-50.

7. Kanat M, Goksugur SB, Ozlu T, Tunckale A, Ozturk B, Ozturk FY, Altuntas Y, Suleymanoglu Y, Atmaca H, Yolcu N, Gonenc I, Delibasi T, Zuhur S, Dikbas O, Aktas G, Karagoz Y, Abdul-Ghani MA. The effect of feto-maternal blood type incompatibility on development of gestational diabetes mellitus. Clin Ter. 2014;165(2):e145-7.

8. Croze ML, Soulage CO. Potential role and therapeutic interests of myoinositol in metabolic diseases. Biochimie. 2013;95(10):1811-27.

9. Schimpf KJ, Meek CC, Leff RD, Phelps DL, Schmitz DJ, Cordle CT. Quantification of myo-inositol, 1,5-anhydro- D-sorbitol, and D-chiro-inositol using highperformance liquid chromatography with electrochemical detection in very small volume clinical samples. Biomed Chromatogr. 2015;29(11):1629-36.

10. Crawford TJ, Crowther CA, Alsweiler J, Brown J. Antenatal dietary supplementation with myo-inositol in women during pregnancy for preventing gestational diabetes. Cochrane Database Syst Rev. 2015: CD011507. https://doi.org/10.1002/14651858.CD011507.pub2.

11. Corrado F, D'Anna R, Di Vieste G, Giordano D, Pintaudi B, Santamaria A, Di Benedetto $A$. The effect of myoinositol supplementation on insulin resistance in patients with gestational diabetes. Diabet Med. 2011;28(8):972-5.

12. Brown J, Crawford TJ, Alsweiler J, Crowther CA. Dietary supplementation with myo-inositol in women during pregnancy for treating gestational. diabetes. Cochrane Database Syst Rev. 2016;9:CD012048. https://doi.org/10. 1002/14651858.CD012048.pub2.

13. Unfer V, Carlomagno G, Dante G, Facchinetti F. Effects of myo-inositol in women with PCOS: a systematic review of randomized controlled trials. Gynecol Endocrinol. 2012;28(7):509-15.

14. Giordano D, Corrado F, Santamaria A, Quattrone S, Pintaudi B, Di Benedetto A, D'Anna R. Effects of myo-inositol supplementation in postmenopausal women with metabolic syndrome: a perspective, randomized, placebocontrolled study. Menopause. 2011;18(1):102-4.

15. Pundir J, Psaroudakis D, Savnur P, Bhide P, Sabatini L, Teede H, Coomarasamy A, Thangaratinam S. Inositol treatment of anovulation in women with polycystic ovary syndrome: a meta-analysis of randomised trials. BJOG. 2018;125(4):509-10.

16. luorno MJ, Jakubowicz DJ, Baillargeon JP, Dillon P, Gunn RD, Allan G, Nestler JE. Effects of d-chiro-inositol in lean women with the polycystic ovary syndrome. Endocr Pract. 2002;8(6):417-23.

17. Malvasi A, Kosmas I, Mynbaev OA, Sparic R, Gustapane S, Guido M, Tinelli A. Can trans resveratrol plus d-chiro-inositol and myo-inositol improve maternal metabolic profile in overweight pregnant patients? Clin Ter. 2017; 168(4):e240-e7.

18. Malvasi A, Casciaro F, Minervini MM, Kosmas I, Mynbaev OA, Pacella E, Monti Condesnitt V, Creanza A, Di Renzo GC, Tinelli A. Myo-inositol, D-chiroinositol, folic acid and manganese in second trimester of pregnancy: a preliminary investigation. Eur Rev Med Pharmacol Sci. 2014;18(2):270-4.

19. Costantino D, Minozzi G, Minozzi E, Guaraldi C. Metabolic and hormonal effects of myo-inositol in women with polycystic ovary syndrome: a doubleblind trial. Eur Rev Med Pharmacol Sci. 2009;13(2):105-10.

20. Gerli S, Papaleo E, Ferrari A, Di Renzo GC. Randomized, double blind placebo-controlled trial: effects of myo-inositol on ovarian function and metabolic factors in women with PCOS. Eur Rev Med Pharmacol Sci. 2007; 11(5):347-54.

21. Kim JI, Kim JC, Kang MJ, Lee MS, Kim JJ, Cha IJ. Effects of pinitol isolated from soybeans on glycaemic control and cardiovascular risk factors in Korean patients with type II diabetes mellitus: a randomized controlled study. Eur J Clin Nutr. 2005;59(3):456-8. 
22. Gerli S, Mignosa M, Di Renzo GC. Effects of inositol on ovarian function and metabolic factors in women with PCOS: a randomized double blind placebo-controlled trial. Eur Rev Med Pharmacol Sci. 2003;7(6):151-9.

23. Nestler JE, Jakubowicz DJ, Reamer P, Gunn RD, Allan G. Ovulatory and metabolic effects of D-chiro-inositol in the polycystic ovary syndrome. N Engl J Med. 1999;340(17):1314-20.

24. D'Anna R, Santamaria A, Cannata ML, Interdonato ML, Giorgianni GM, Granese R, Corrado F, Bitto A. Effects of a new flavonoid and Myo-inositol supplement on some biomarkers of cardiovascular risk in postmenopausal women: a randomized trial. Int J Endocrinol. 2014;2014:653561.

25. Capasso I, Esposito E, Maurea N, Montella M, Crispo A, De Laurentiis M, D'Aiuto M, Frasci G, Botti G, Grimaldi M, Cavalcanti E, Esposito G, Fucito A, Brillante G, D'Aiuto G, Ciliberto G. Combination of inositol and alpha lipoic acid in metabolic syndrome-affected women: a randomized placebocontrolled trial. Trials. 2013;14:273.

26. Santamaria A, Giordano D, Corrado F, Pintaudi B, Interdonato ML, Vieste GD, Benedetto AD, D'Anna R. One-year effects of myo-inositol supplementation in postmenopausal women with metabolic syndrome. Climacteric. 2012; 15(5):490-5.

27. Cianci A, Panella M, Fichera M, Falduzzi C, Bartolo M, Caruso S. D-chiroinositol and alpha lipoic acid treatment of metabolic and menses disorders in women with PCOS. Gynecol Endocrinol. 2015;31(6):483-6.

28. Minozzi M, Costantino D, Guaraldi C, Unfer $\mathrm{V}$. The effect of a combination therapy with myo-inositol and a combined oral contraceptive pill versus a combined oral contraceptive pill alone on metabolic, endocrine, and clinical parameters in polycystic ovary syndrome. Gynecol Endocrinol. 2011;27(11):920-4.

29. Chapman K. Can people make healthy changes to their diet and maintain them in the long term? A review of the evidence. Appetite. 2010;54(3):433-41.

30. Roumen C, Blaak EE, Corpeleijn E. Lifestyle intervention for prevention of diabetes: determinants of success for future implementation. Nutr Rev. 2009;67(3):132-46.

31. Nieuwenhuis-Ruifrok AE, Kuchenbecker WK, Hoek A, Middleton P, Norman RJ. Insulin sensitizing drugs for weight loss in women of reproductive age who are overweight or obese: systematic review and meta-analysis. Hum Reprod Update. 2009;15(1):57-68.

32. McQueen MJ, Hawken S, Wang X, Ounpuu S, Sniderman A, Probstfield J, Steyn K, Sanderson JE, Hasani M, Volkova E, Kazmi K, Yusuf S, INTERHEART study investigators. Lipids, lipoproteins, and apolipoproteins as risk markers of myocardial infarction in 52 countries (the INTERHEART study): a casecontrol study. Lancet. 2008;372(9634):224-33.

33. Sperling LS, Mechanick JI, Neeland IJ, Herrick CJ, Despres JP, Ndumele CE, Vijayaraghavan K, Handelsman Y, Puckrein GA, Araneta MR, Blum QK, Collins KK, Cook S, Dhurandhar NV, Dixon DL, Egan BM, Ferdinand DP, Herman LM, Hessen SE, Jacobson TA, Pate RR, Ratner RE, Brinton EA, Forker AD, Ritzenthaler LL, Grundy SM. The CardioMetabolic health alliance: working toward a new care model for the metabolic syndrome. J Am Coll Cardiol. 2015;66(9):1050-67.

34. Marazzi G, Cacciotti L, Pelliccia F, laia L, Volterrani M, Caminiti G, Sposato B, Massaro R, Grieco F, Rosano G. Long-term effects of nutraceuticals (berberine, red yeast rice, policosanol) in elderly hypercholesterolemic patients. Adv Ther. 2011;28(12):1105-13.

35. Sirtori CR, Galli C, Anderson JW, Arnoldi A. Nutritional and nutraceutical approaches to dyslipidemia and atherosclerosis prevention: focus on dietary proteins. Atherosclerosis. 2009;203(11):8-17.

36. Scicchitano P, Cameli M, Maiello M, Modesti PA, Muiesan ML, Novo S, Palmiero P, Saba PS, Pedrinelli R, Ciccone MM. Nutraceuticals and dyslipidaemia: beyond the common therapeutics. J Funct Foods. 2014;6:11-32.

37. de Jong A, Plat J, Mensink RP. Metabolic effects of plant sterols and stanols (review). J Nutr Biochem. 2003;14(7):362-9.

38. Hanhineva K, Torronen R, Bondia-Pons I, Pekkinen J, Kolehmainen M, Mykkanen H, Poutanen K. Impact of dietary polyphenols on carbohydrate metabolism. Int J Mol Sci. 2010;11(4):1365-402.

39. Baillargeon JP, luorno MJ, Apridonidze T, Nestler JE. Uncoupling between insulin and release of a D-chiro-inositol-containing inositolphosphoglycan mediator of insulin action in obese women with polycystic ovary syndrome. Metab Syndr Relat Disord. 2010;8(2):127-36.

40. Ortmeyer HK, Huang LC, Zhang L, Hansen BC, Larner J. Chiroinositol deficiency and insulin resistance. II. Acute effects of D-chiroinositol administration in streptozotocin-diabetic rats, normal rats given a glucose load, and spontaneously insulin-resistant rhesus monkeys. Endocrinology. 1993;132(2):646-51.
41. Choi MS, Lee MK, Jung UJ, Kim HJ, Do GM, Park YB, Jeon SM. Metabolic response of soy pinitol on lipid-lowering, antioxidant and hepatoprotective action in hamsters fed-high fat and high cholesterol diet. Mol Nutr Food Res. 2009;53(6):751-9.

42. Fruhbeck G, Gomez-Ambrosi J, Muruzabal FJ, Burrell MA. The adipocyte: a model for integration of endocrine and metabolic signaling in energy metabolism regulation. Am J Physiol Endocrinol Metab. 2001;280(6):E827-47.

43. Yamauchi T, Kamon J, Waki H, Terauchi Y, Kubota N, Hara K, Mori Y, Ide T, Murakami K, Tsuboyama-Kasaoka N, Ezaki O, Akanuma Y, Gavrilova O, Vinson C, Reitman ML, Kagechika H, Shudo K, Yoda M, Nakano Y, Tobe K, Nagai R, Kimura S, Tomita M, Froguel P, Kadowaki T. The fat-derived hormone adiponectin reverses insulin resistance associated with both lipoatrophy and obesity. Nat Med. 2001;7(8):941-6.

\section{Ready to submit your research? Choose BMC and benefit from:}

- fast, convenient online submission

- thorough peer review by experienced researchers in your field

- rapid publication on acceptance

- support for research data, including large and complex data types

- gold Open Access which fosters wider collaboration and increased citations

- maximum visibility for your research: over $100 \mathrm{M}$ website views per year

At BMC, research is always in progress.

Learn more biomedcentral.com/submissions 